\title{
Peroxynitrite mediated linoleic acid oxidation and tyrosine nitration in the presence of synthetic neuromelanins ${ }^{\star \star}$
}

\author{
Krystyna Stępień ${ }^{凶}$, Adam Wilczok, Alicja Zajdel, Anna Dzierżęga-Lęcznar \\ and Tadeusz Wilczok
}

\begin{abstract}
Department of Molecular Biology, Biochemistry and Biopharmacy, Faculty of Pharmacy, Medical University of Silesia, Sosnowiec, Poland
\end{abstract}

Received: 25 September, 2000; revised: 8 November, 2000; accepted: 24 November, 2000

Key words: DA-melanin, CysDA-melanin, DA/CysDA-copolymers, neuromelanin, peroxynitrite, linoleic acid, 3-nitrotyrosine, peroxidation, nitration

\begin{abstract}
Peroxynitrite-mediated linoleic acid oxidation and tyrosine nitration were analysed in the presence of synthetic model neuromelanins: dopamine (DA) -melanin, cysteinyldopamine (CysDA) -melanin and various DA/CysDA copolymers. The presence of melanin significantly decreased the amount of 3-nitrotyrosine formed. This inhibitory effect depended on the type and concentration of melanin polymer. It was found that incorporation of CysDA-derived units into melanin attenuated its protective effect on tyrosine nitration induced by peroxynitrite. In the presence of bicarbonate, the melanins also inhibited 3-nitrotyrosine formation in a concentration dependent manner, although the extent of inhibition was lower than in the absence of bicarbonate. The tested melanins inhibited peroxynitrite-induced formation of linoleic acid hydroperoxides, both in the absence and in the presence of bicarbonate. In the presence of bicarbonate, among the oxidation products appeared 4-hydroxynonenal (HNE). CysDA-melanin inhibited the formation of HNE, while DA-melanin did not affect the aldehyde level. The results of the presented study suggest that neuromelanin can act as a natural scavenger of peroxynitrite.
\end{abstract}

\footnotetext{
^Presented at the 5th Symposium on "Free Radicals in Biology and Medicine” Łódź, Poland, 2000.

This work was supported by grant No. 484/PO5/98/15 of the State Committee for Scientific Research (KBN, Poland).

${ }^{\circledR}$ Corresponding author: Krystyna Stępień, Department of Molecular Biology, Biochemistry and Biopharmacy, Faculty of Pharmacy, Medical University of Silesia, Narcyzów 1, 41-200 Sosnowiec, Poland; tel: (48 32) 291 0099; fax: (48 32) 291 7496, e-mail: kstepien@farmant.slam.katowice.pl

Abbreviations: 5-S-CysDA, 5-S-cysteinyldopamine; 13-HPODE, 13(S)-hydroperoxy-(9Z,11E)-octadecadienoic acid; 13-HODE, 13(S)-hydroxy-(9Z,11E)-octadecadienoic acid; HNE, 4-hydroxy-2-nonenal; DA-melanin, dopamine-melanin; CysDA-melanin, 5-S-cysteinyldopamine-melanin; DTPA, diethylenetriaminepentaacetic acid.
} 
Peroxynitrite $\left(\mathrm{ONOO}^{-} / \mathrm{ONOOH}\right)$ is thought to be involved in many pathological processes associated with excessive nitric oxide (NO) production in biological systems (Beckman \& Koppenol, 1996; Bartosz, 1996; Patel et al., 1999; Murphy, 1999). NO reacts with the superoxide radical anion $\left(\mathrm{O}_{2}^{--}\right)$to form the peroxynitrite anion at nearly the diffusionlimited rate (Huie \& Padmaja, 1993). Peroxynitrite is a powerful oxidant and nitrating agent which is capable of modifying lipids (Radi et al., 1991; O'Donnell et al., 1999a), proteins (Ischiropoulos \& Al-Mehdi, 1995; Alayash et al., 1998) and DNA (Yermilov et al., 1995; Douki \& Cadet, 1996; Szabo et al., 1996). Nitration of free and protein-bound tyrosine leading to the formation of 3-nitrotyrosine is a well established reaction of peroxynitrite (Ischiropoulos et al., 1992; van der Vliet et al., 1995; Ischiropoulos, 1998). It has been shown that 3-nitrotyrosine formation is catalysed by $\mathrm{CO}_{2}$, which reacts with the peroxynitrite anion at physiological $\mathrm{pH}$ to form a short-lived intermediate identified as the $\mathrm{ONO}_{2} \mathrm{CO}_{2}{ }^{-}$adduct (nitrosoperoxycarbonate anion) (Lymar \& Hurst, 1995; Lymar et al., 1996; Gow et al., 1996). The reaction of $\mathrm{ONOO}^{-}$with $\mathrm{CO}_{2}$ is one of the fastest reactions known for peroxynitrite $\left(k=3.0 \times 10^{4}\right.$ $\mathrm{M}^{-1} \mathrm{~s}^{-1}$ ) (Lymar \& Hurst, 1995) and therefore can affect its reactivity towards potential biological targets. At physiological concentrations of $\mathrm{CO}_{2}$, peroxynitrite-dependent nitration is stimulated, while oxidation is inhibited (Gow et al., 1996; Berlett et al., 1998; Radi et al., 1999).

3-Nitrotyrosine has been suggested as a marker of peroxynitrite-mediated damage in a variety of disease states, including neurodegenerative disorders such as Alzheimer's disease (Smith et al., 1997) and Parkinson's disease (Good et al., 1998; Ara et al., 1998). However, tyrosine nitration can also be caused by other biochemical pathways (Ischiropoulos, 1998; Pfeiffer et al., 2000).

Neuromelanin, a dark pigment that deposits with age in the cytoplasm of nigrostriatal dopaminergic neurons, originates from the oxidative pathway of dopamine (DA) metabolism in the human brain (Graham, 1978; Marsden, 1983). The synthesis of neuromelanin is initiated by the oxidation of DA to its o-quinone, which can undergo intramolecular cyclization and further oxidation to indoles (Graham, 1978; Costa et al., 1992), or can react with the thiol group of cysteine to give cysteinyl conjugates, mainly 5-S-cysteinyldopamine (5-S-CysDA) (Tse et al., 1976; Ito et al., 1986; Zhang \& Dryhurst, 1995). These conjugates are easily oxidized (more easily than DA) to form benzothiazine derivatives (Shen \& Dryhurst, 1996). Degradative studies of neuromelanin isolated from human substantia nigra have demonstrated that the pigment is a copolymer of eumelanin and phaeomelanin, and consists of indole-type and benzothiazinetype units (Carstam et al., 1991; Odh et al., 1994). It has been postulated that neuromelanin formation is an autoxidative process catalysed by iron and other transition metals (Rodgers \& Curzon, 1975; Fornstedt et al., 1989; D'Ischia \& Prota, 1997), although enzymes such as prostaglandin $\mathrm{H}$ synthase (Hastings, 1995), lipoxygenase (Rosei et al., 1994) and peroxidase (Okun, 1997) are capable of oxidizing DA to DA-quinone in vitro. The ability of peroxynitrite to promote DA oxidation has been also demonstrated (Kerry \& Rice-Evans, 1999; LaVoie \& Hastings, 1999).

Recently, we have shown that synthetic DA-melanin inhibited peroxynitrite-mediated nitration of free tyrosine, loss of tryptophan residues in bovine serum albumin and $\mathrm{Ca}^{2+}$-ATPase inactivation (Stępień et al., 2000). In this work we investigated the effect of synthetic neuromelanins derived from DA and 5-S-CysDA on peroxynitrite-induced tyrosine nitration and linoleic acid oxidation.

\section{MATERIALS AND METHODS}

Chemicals. Mushroom tyrosinase (6680 $\mathrm{U} / \mathrm{mg}$ of solid; EC 1.14.18.1), linoleic acid 
(99\% by capillary GC), 13(S)-hydroperoxy(9Z, 11E)-octadecadienoic acid (13-HPODE), 13(S)-hydroxy-(9Z,11E)-octadecadienoic acid (13-HODE), 4-hydroxy-2-nonenal (HNE) were purchased from Sigma-Aldrich Co. All the other reagents were also obtained from Sigma-Aldrich Co. and were of analytical grade. Solvents of HPLC grade and type I deionized water (Barnstead, NANOpure) were used.

Preparation of 5-S-CysDA and synthetic neuromelanins. 5-S-Cysteinyldopamine was obtained by tyrosinase-catalysed oxidation of dopamine in the presence of cysteine, and purified by ion-exchange chromatography (Dowex 50Wx2) according to Ito et al. (1986). Synthetic models of neuromelanin were prepared by oxidative polymerization of dopamine (DA-melanin) or 5-S-cysteinyldopamine (CysDA-melanin), and by copolymerization of both precursors at molar ratios $3: 1$ (DA/CysDA(3:1)-melanin) and $1: 1$ (DA/ CysDA(1:1)-melanin). Solutions of the melanin precursors (total concentration $5 \mathrm{mM}$ ) in phosphate buffer (50 mM, pH 7.4) were incubated at $37^{\circ} \mathrm{C}$ for $48 \mathrm{~h}$. The insoluble melanins formed during such oxidation were separated by centrifugation $(3000 \times \boldsymbol{g})$, washed with water and stored as aqueous suspensions of known concentrations. Elemental analysis of the melanin samples was performed by the Center for Molecular and Macromolecular Research of the Polish Academy of Sciences in Łódź (Poland).

Synthesis of peroxynitrite. Peroxynitrite was synthesised according to the method of Uppu and Pryor (1996), using a $2 \mathrm{M} \mathrm{H}_{2} \mathrm{O}_{2}$ solution in $\mathrm{NaOH}$ (100 ml, $\mathrm{pH} 13$ ) and isoamyl nitrite $(0.2 \mathrm{~mol})$. The aqueous phase that contained peroxynitrite was separated after centrifugation and washed with dichloromethane $(6 \times 100 \mathrm{ml})$ to remove the contaminating isoamyl alcohol and traces of isoamyl nitrite. The unreacted $\mathrm{H}_{2} \mathrm{O}_{2}$ was removed by passing the aqueous phase through a column of $\mathrm{MnO}_{2}(25 \mathrm{~g})$ prewashed with water $(20 \mathrm{ml})$ and $0.5 \mathrm{M} \mathrm{NaOH}(20 \mathrm{ml})$. A stock solution of peroxynitrite was stored frozen at $-80^{\circ} \mathrm{C}$. The peroxynitrite concentration was determined spectrophotometrically at $302 \mathrm{~nm}$ using a molar absorption coefficient of $1700 \mathrm{M}^{-1} \mathrm{~cm}^{-1}$ (Bohle et al., 1996) before each experiment, and appropriate amounts of peroxynitrite solution were added to reaction mixtures. A drop of peroxynitrite was placed on the test tube wall and the samples were immediately vortexed for $30 \mathrm{~s}$. In control experiments, decomposed peroxynitrite was used (Stępień et al., 2000).

Tyrosine nitration. Peroxynitrite (final concentration $1 \mathrm{mM}$ ) was added to solutions of tyrosine $(1 \mathrm{mM})$ in sodium phosphate buffer (0.1 M, pH 7.4) containing $0.1 \mathrm{mM}$ diethylenetriaminepentaacetic acid (DTPA) and various amounts of model melanins $(50-800 \mu \mathrm{g} / \mathrm{ml})$. In a separate set of experiments, the reaction medium was supplemented with sodium bicarbonate $(20 \mathrm{mM})$. Bicarbonate was introduced 2 min before the addition of peroxynitrite ( $\mathrm{pH}$ of the solution increased to 7.6). Incubations were carried out for $30 \mathrm{~min}$ at room temperature. The formation of 3-nitrotyrosine was quantified by HPLC and expressed as a percent of the control incubated without melanin.

Linoleic acid oxidation. The reaction mixtures contained linoleic acid ( $1 \mathrm{mM}$ ) dispersed in sodium phosphate buffer (0.1 M, $\mathrm{pH} 7.4)$, DTPA $(0.1 \mathrm{mM})$, various concentrations of DA-melanin or CysDA-melanin (10-200 $\mu \mathrm{g}$ / $\mathrm{ml}$ ) and 0 or $20 \mathrm{mM}$ of sodium bicarbonate. The oxidation was initiated by adding peroxynitrite to a final concentration of 4 $\mathrm{mM}$. After $2 \mathrm{~h}$ of incubation at room temperature, each sample was diluted with methanol $(1: 1, \mathrm{v} / \mathrm{v})$ and directly analysed by HPLC.

HPLC analysis. Reverse-phase HPLC was performed with a Hewlett-Packard model 1050 liquid chromatograph equipped with a HP 1100 diode array detector and interfaced to a HPLC ChemStation (HP). Each sample was filtered (filter Millex GV13, pore diameter $0.22 \mu \mathrm{m}$; Millipore) to remove melanin and then the reaction products were separated on an Eurospher 100 C18 column (particle size 
$5 \mu \mathrm{m}, 250 \times 4 \mathrm{~mm}$; Knauer) at $35^{\circ} \mathrm{C}$. 3-Nitrotyrosine and tyrosine were eluted isocratically with $50 \mathrm{mM} \mathrm{KH} \mathrm{KO}_{4}(\mathrm{pH} \mathrm{3})$ and methanol (92:8) and detected at $276 \mathrm{~nm}$ (tyrosine was eluted at $4.6 \mathrm{~min}$ and 3-nitrotyrosine at 12.4 min). Linoleic acid oxidation products were separated using water (A) and acetonitryle (B) containing $0.2 \%$ phosphoric acid and the following gradient programme: $0 \mathrm{~min} 50 \% \mathrm{~A}$ : $50 \%$ B, $2 \min 50 \%$ A:50\% B, 16 min 17\% A: 83\% $\mathrm{B}$ and $17 \mathrm{~min}$ 100\% B. HNE, 13-HODE and four linoleic acid hydroperoxides isomers were identified by matching their retention times and UV-Vis spectra with respective standards. The observed retention times were 5.2 min, $19.1 \mathrm{~min}, 21.1 \mathrm{~min}, 21.9 \mathrm{~min}, 24.2 \mathrm{~min}$ and $25.5 \mathrm{~min}$, respectively. The amounts of 3-nitrotyrosine, 13-HODE and HNE were calculated with respect to the appropriate calibration curves. Quantifications of linoleic acid hydroperoxides were made using 13-HPODE as a standard.

The results are expressed as mean values \pm S.D. calculated from three or more independent experiments.

\section{RESULTS}

Elemental analysis revealed that CysDAmelanin, DA/CysDA(1:1)-melanin and DA/ CysDA(3:1)-melanin contained 11.4\%, 9.1\% and $5.8 \%$ sulphur, respectively. These data indicate that phaeomelanin-type units derived from 5-S-CysDA have been indeed incorporated into the melanin polymers in different proportions.

To determine the effect of synthetic neuromelanins on tyrosine nitration mediated by peroxynitrite, formation of 3-nitrotyrosine was measured by HPLC. In the absence of melanin, the yield of 3-nitrotyrosine was $95 \pm 6 \mu \mathrm{M}(\mathrm{n}=12)$ after the addition of $1 \mathrm{mM}$ $\mathrm{ONOO}^{-}$. The presence of melanin in the reaction medium significantly decreased the amount of 3-nitrotyrosine formed. As shown in Fig. 1, this inhibitory effect depended on the type and concentration of melanin polymer. At low concentrations (50 and $100 \mu \mathrm{g}$ / $\mathrm{ml}$ ), all the melanins tested had no effect on peroxynitrite-mediated nitration of tyrosine but a further increase in melanin concentrations caused a gradual decrease in the yield of 3-nitrotyrosine. DA-melanin was the most efficient inhibitor of 3-nitrotyrosine formation, while CysDA-melanin and DA/CysDA (1:1)melanin were the least effective and their inhibitory effects were virtually the same at any concentration employed. Addition of $20 \mathrm{mM}$ bicarbonate, prior to peroxynitrite, enhanced the level of 3-nitrotyrosine in controls about 1.5-fold (132 $\pm 7 \mu \mathrm{M}$ of 3-nitrotyrosine; $\mathrm{n}=12$ ). In the presence of bicarbonate, the melanins inhibited 3-nitrotyrosine formation in a concentration dependent manner, although the extent of inhibition was lower than in the absence of bicarbonate (Fig. 1).

The influence of DA-melanin and CysDAmelanin on the oxidation of linoleic acid by peroxynitrite was investigated. Treatment of linoleic acid with peroxynitrite led to the formation of isomeric hydroperoxides with cis, trans 13-HPODE and cis, trans 9-HPODE being the major products. The tested melanins inhibited formation of HPODEs, and the inhibition extent, similar for both melanins, depended on their concentration (Fig. 2A). When amounts of 13-HODE were analysed, only a little increase was observed for CysDA-melanin (maximally $1 \pm 0.1 \mu \mathrm{M}$ HODE for $200 \mu \mathrm{g} / \mathrm{ml}$ CysDA-melanin), while the effect of DA-melanin did not look significant. In the presence of bicarbonate, in control samples, the observed levels of linoleic acid hydroperoxides were about two times lower than in the absence of bicarbonate (Fig. 2). The addition of DA-melanin and CysDA-melanin caused a further decrease of HPODE concentration while the amounts of HODE remained almost unchanged. In experiments carried out with added bicarbonate, 4-hydroxy-2-nonenal, which was absent in the samples without bicarbonate, appeared among the analysed oxidation products. DA-melanin did not affect 

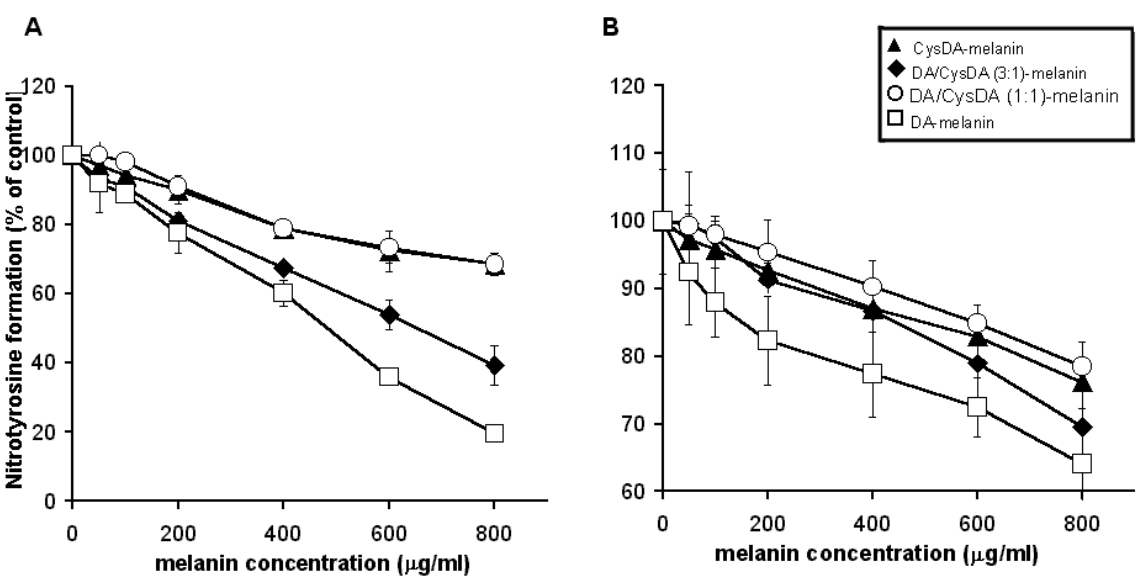

Figure 1. Effect of melanins on peroxynitritemediated 3-nitrotyrosine formation.

Peroxynitrite (final concentration $1 \mathrm{mM}$ ) was added to solutions of tyrosine ( $1 \mathrm{mM}$ ) in phosphate buffer (100 $\mathrm{mM}, \mathrm{pH}$ 7.4) containing indicated concentrations of melanins in the absence (A) or in the presence (B) of 20 $\mathrm{mM}$ sodium bicarbonate.

the HNE level at all, whereas CysDA-melanin showed an inhibiting effect (Fig. 3).

\section{DISCUSSION}

Recently, we have demonstrated the ability of DA-melanin to protect against nitrating action of peroxynitrite (Stępień et al., 2000). In this study, the effect of model neuromelanins derived from CysDA and from DA/CysDA mixtures on peroxynitrite-mediated tyrosine nitration was investigated and compared to component into the eumelanin polymer attenuates its protective effect on tyrosine nitration induced by peroxynitrite. In the presence of $20 \mathrm{mM}$ bicarbonate (which is in equilibrium with approximately $1 \mathrm{mM} \mathrm{CO}_{2}$ ) stimulation of tyrosine nitration in the control was observed; this is in agreement with the data of other authors (Lymar et al., 1996; Lehnig, 1999). The observed stimulation depends only on the formation of the highly reactive peroxynitrite$\mathrm{CO}_{2}$ adduct and does not depend on the $\mathrm{pH}$ change caused by bicarbonate addition. As shown by Lymar et al. (1996), the $\mathrm{CO}_{2}$-ca-
A

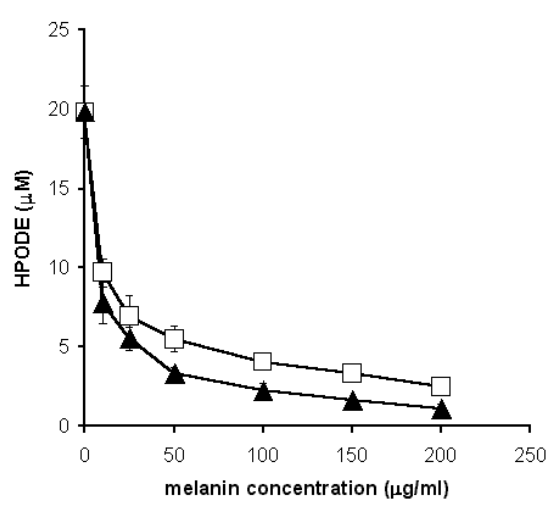

B

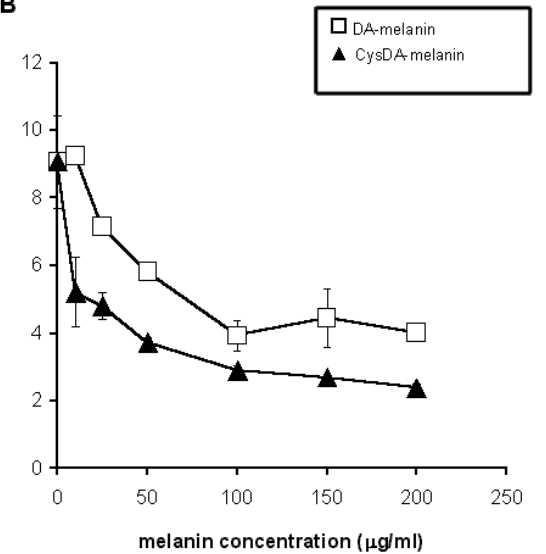

Figure 2. Effect of melanins on peroxynitritemediated linoleic acid hydroperoxides formation.

Peroxynitrite (final concentration $4 \mathrm{mM}$ ) was added to solutions of linoleic acid (1 $\mathrm{mM}$ ) in phosphate buffer (100 mM, pH 7.4) containing indicated concentrations of melanins in the absence (A) or in the presence (B) of $20 \mathrm{mM}$ sodium bicarbonate. the effect of DA-melanin. It was found that all the melanins tested significantly inhibited the formation of 3-nitrotyrosine but DA-melanin was a more efficient inhibitor than CysDAmelanin and DA/CysDA-melanins. This indicates that incorporation of the phaeomelanin talysed 3-nitrotyrosine formation is not influenced by $\mathrm{pH}$ in the range of 5-8. Addition of the melanins diminished the levels of 3-nitrotyrosine formed, indicating their ability to protect against the nitrating action of peroxynitrite- $\mathrm{CO}_{2}$ adduct. 
Study of the effect of the melanins on peroxynitrite-induced oxidation of linoleic acid demonstrated that both DA-melanin and CysDA-melanin significantly decreased the

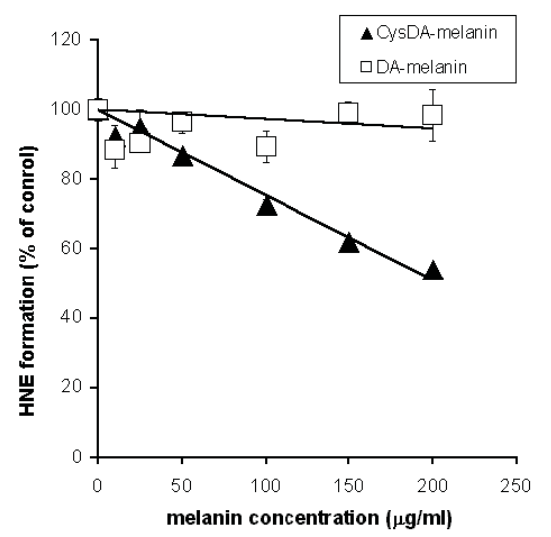

Figure 3. Decrease of 4-hydroxynonenal induced by melanins during peroxynitrite $/ \mathrm{CO}_{2}$-mediated linoleic acid oxidation.

Peroxynitrite (final concentration $4 \mathrm{mM}$ ) was added to solutions of linoleic acid (1 $\mathrm{mM})$ in phosphate buffer (100 mM, pH 7.4) containing indicated concentration of melanins in the presence of $20 \mathrm{mM}$ sodium bicarbonate.

yield of linoleic acid hydroperoxides formed. As melanins are capable of reducing linoleic acid hydroperoxides to its hydroxyl derivatives (Stępień et al., 1998; Wilczok et al., 1999), the formation of 13-HODE was analysed simultaneously with HPODEs after treatment of linoleic acid with peroxynitrite in the presence of the melanins. A little increase in the amount of 13-HODE formed was observed only for CysDA-melanin at the highest concentration applied. These experiments showed that DA-melanin and CysDA-melanin indeed inhibited linoleic acid oxidation induced by peroxynitrite. When the peroxynitrite-mediated oxidation of linoleic acid was carried out in the presence of bicarbonate, the levels of HPODEs were attenuated and HNE was detected among the oxidation products. This aldehyde was not found after the reaction of linoleic acid with peroxynitrite in the absence of bicarbonate. HNE is the secondary oxidation product derived from omega-6- polyunsaturated fatty acids such as 20:4 and 18:2
(Comporti, 1998). This suggests that the peroxynitrite- $\mathrm{CO}_{2}$ adduct is able to decompose linoleic acid hydroperoxides. CysDA-melanin inhibited the formation of HNE, while DA-melanin did not affect the aldehyde level. The results indicate that CysDA-melanin is a more effective inhibitor of peroxynitrite $/ \mathrm{CO}_{2}$-mediated linoleic acid oxidation than DA-melanin.

O’Donnell et al. (1999a; 1999b) have shown that treatment of linoleic acid with peroxynitrite leads to the formation of nitrated linoleate species ( $\left.\mathrm{LNO}_{2} / \mathrm{LONO}\right)$, in addition to HPODE and HODE. In our study, we did not detect any linoleic acid nitration products. In our experiment, peroxynitrite was introduced to linoleic acid by bolus addition and products of the reaction were analysed without extraction, which requires acidification of samples and may cause secondary reactions. In the studies described by O'Donnell et al. (1999a; 1999b), the diluted solution of peroxynitrite in $0.1 \mathrm{M} \mathrm{NaOH}$ was infused at a constant rate over 15 min into the linoleate emulsion and an equal volume of $0.1 \mathrm{M} \mathrm{HCl}$ was simultaneously infused to keep a constant $\mathrm{pH}$ value. These authors noted that "relative yields of oxidized vs nitrated products are likely to vary depending on the administration method chosen".

The peroxynitrite anion is relatively unreactive, however, protonation or addition of $\mathrm{CO}_{2}$ generates a reactive species that can either interact with target compounds or undergo isomerization to $\mathrm{NO}_{3}^{-}$ion (Uppu et al., 1996). Currently proposed mechanisms of peroxynitrite reactivity involve the spontaneous decomposition of peroxynitrous acid (HOONO) with the generation of $\mathrm{OH}$ and $\mathrm{NO}_{2}$ radicals (Richeson et al., 1998; Hodges \& Ingold, 1999; Coddington, 1999). Carbon dioxide enhances the rate of decay of peroxynitrite to form $\mathrm{ONOOCO}_{2}{ }^{-}$which can be a source of $\mathrm{CO}_{3}^{-}$and $\mathrm{NO}_{2}^{-}$(Goldstein \& Czapski, 1998; 1999). The stimulating effect of $\mathrm{CO}_{2}$ on tyrosine nitration induced by peroxynitrite is explained by the participation of $\mathrm{CO}_{3}^{-}$in 
one-electron oxidation of tyrosine, leading to tyrosyl radical (Zhang et al., 1997; Lehnig 1999).

Melanins are known to be able to scavenge the hydroxyl radicals (Sarna et al., 1986). Interactions of synthetic eu- and phaeo-melanins derived from 3,4-dihydroxyphenylalanine with strong oxidising radicals such as $\mathrm{NO}_{2}$ were described (Różanowska et al., 1999). The observed inhibition of 3-nitrotyrosine formation by all the melanins tested, both in the absence and presence of added bicarbonate, suggests that the model neuromelanins are capable of scavenging $\mathrm{NO}_{2}$ radicals.

The results of the presented study suggest that neuromelanin can act as natural scavenger of peroxynitrite. As peroxynitrite is proposed to be a mediator of neurotoxic processes associated with Parkinson's disease, a protective effect of neuromelanin against peroxynitrite may be of physiological importance.

\section{R E F E R E N C E S}

Alayash, A.I., Ryan, B.A. \& Cashon, R.E. (1998) Peroxynitrite-mediated heme oxidation and protein modification of native and chemically modified hemoglobins. Arch. Biochem. Biophys. 349, 65-73.

Ara, J., Przedborski, S., Naini, A.B., Jackson-Lewis, D., Trifiletti, R.R., Horwitz, H. \& Ischiropoulos, H. (1998) Inactivation of tyrosine hydroxylase by nitrating following exposure to peroxynitrite and 1-methyl-4-phenyl1,2,3,6-tetrahydropyridine (MPTP). Proc. Natl. Acad. Sci. U.S.A. 95, 7659-7663.

Bartosz, G. (1996) Peroxynitrite: Mediator of the toxic action of nitric oxide. Acta Biochim. Polon. 43, 645-660.

Beckman, J.S. \& Koppenol, W.H. (1996) Nitric oxide, superoxide and peroxynitrite: The good, the bad and the ugly. Am. J. Physiol. Cell Physiol. 271, C1424-C1437.
Berlett, B.S., Levine, R.L. \& Stadtman, E.R. (1998) Carbon dioxide stimulates peroxynitrite-mediated nitration of tyrosine residues and inhibits oxidation of methionine residues of glutamine synthetase; both modifications mimic effects of adenylylation. Proc. Natl. Acad. Sci. U.S.A. 95, 2784-2789.

Bohle, D.S., Glassbrenner, P.A. \& Hansert, B. (1996) Syntheses of pure tetramethylammonium peroxynitrite. Methods Enzymol. 269, 302-311.

Carstam, R., Brinck, C., Hindemith-Augustsson, A., Rorsman, H. \& Rosengren, E. (1991) The neuromelanin of the human substantia nigra. Biochim. Biophys. Acta 1097, 152-160.

Coddington, J.W., Hurst, J.K. \& Lymar, V. (1999) Hydroxyl radical formation during peroxynitrous acid decomposition. J. Am. Chem. Soc. 121, 2438-2443.

Comporti, M. (1998) Lipid peroxidation and biogenic aldehydes: From the identification of 4-hydroxynonenal to further achievements in biopathology. Free Radical Res. 28, 623-635.

Costa, C., Bertazzo, A., Allegri, G., Toffano, G., Curcuruto, O. \& Traldi, P. (1992) Melanin biosynthesis from dopamine. II. A mass spectrometric and collisional spectroscopic investigation. Pigment Cell Res. 5, 122-131.

D’Ischia, M. \& Prota, G. (1997) Biosynthesis, structure, and function of neuromelanin and its relation to Parkinson's disease: A critical update. Pigment Cell Res. 10, 370-376.

Douki, T. \& Cadet, J. (1996) Peroxynitrite mediated oxidation of purine bases of nucleosides and isolated DNA. Free Radical Res. 24, 369-380.

Fornstedt, B., Brun, A., Rosengren, E. \& Carlsson, A. (1989) The apparent autoxidation rate of catechols in dopamine-rich regions of human brains increases with the degree of depigmentation of substantia nigra. J. Neural Transm. 1, 279-295.

Goldstein, S. \& Czapski, G. (1998) Formation of peroxynitrate from the reaction of peroxynitrite with $\mathrm{CO}_{2}$ : Evidence for carbonate radical production. J. Am. Chem. Soc. 120, 3458-3463. 
Goldstein, S. \& Czapski, G. (1999) Viscosity effects on the reaction of peroxynitrite with $\mathrm{CO}_{2}$ : Evidence for radical formation in a solvent cage. J. Am. Chem. Soc. 121, 2444-2447.

Good, P.F., Hsu, A., Werner, P., Perl, P.D. \& Olanow, C.W. (1998) Protein nitration in Parkinson's disease. J. Neuropathol. Exp. Neurol. 57, 338-342.

Gow, A., Duran, S., Thom, S.R. \& Ischiropoulos, H. (1996) Carbon dioxide enhancement of peroxynitrite-mediated protein tyrosine nitration. Arch. Biochem. Biophys. 333, 42-48.

Graham, D.G. (1978) Oxidative pathways for catecholamines in the genesis of neuromelanin and cytotoxic quinones. Mol. Pharmacol. 14, 633-643.

Hastings, T.G. (1995) Enzymatic oxidation of dopamine: The role of prostaglandin $\mathrm{H}$ synthase. J. Neurochem. 64, 919-924.

Hodges, G.R. \& Ingold, K.U. (1999) Cage-escape of geminate radical pairs can produce peroxynitrate from peroxynitrite under a wide variety of experimental conditions. J. Am. Chem. Soc. 121, 10695-10701.

Huie, R.E. \& Padmaja, S. (1993) The reaction of NO with superoxide. Free Radical Res. Commun. 18, 195-199.

Ischiropoulos, H. \& Al-Mehdi, A.B. (1995) Peroxynitrite-mediated oxidative protein modification. FEBS Lett. 364, 279-282.

Ischiropoulos, H. (1998) Biological tyrosine nitration: A pathophysiological function of nitric oxide and reactive oxygen species. Arch. Biochem. Biophys. 356, 1-11.

Ischiropoulos, H., Zhu, L., Chen, J., Tsai, M., Martin, J.S., Smith, C.D. \& Beckman, J.S. (1992) Peroxynitrite-mediated tyrosine nitration catalyzed by superoxide dismutase. Arch. Biochem. Biophys. 298, 431-437.

Ito, S., Fujita, K., Yoshioka, M., Sienko, D. \& Nagatsu, T. (1986) Identification of 5-S- and 2-S-cysteinyldopamine and 5-S-glutathionyldopamine formed from dopamine by high-performance liquid chromatography with electrochemical detection. J. Chromatogr. 375, 134-140.
Kerry, N. \& Rice-Evans, C. (1999) Inhibition of peroxynitrite-mediated oxidation of dopamine by flavonoid and phenolic antioxidants and their structural relationships. J. Neurochem. 73, 247-253.

LaVoie, M. \& Hastings, T.G. (1999) Peroxynitriteand nitrite-induced oxidation of dopamine: Implications for nitric oxide in dopaminergic cell loss. J. Neurochem. 73, 2546-2554.

Lehnig, M. (1999) Radical mechanisms of the decomposition of peroxynitrite and the peroxynitrite- $\mathrm{CO}_{2}$ adduct and of reactions with L-tyrosine and related compounds as studied by ${ }^{15} \mathrm{~N}$ chemically induced dynamic nuclear polarization. Arch. Biochem. Biophys. 368, 303-318.

Lymar, S.V. \& Hurst, J.K. (1995) Rapid reaction between peroxynitrite ion and carbon dioxide: Implications for biological activity. J. Am. Chem. Soc. 117, 8867-8868.

Lymar, S.V., Jiang, Q. \& Hurst, J.K. (1996) Mechanism of carbon dioxide-catalyzed oxidation of tyrosine by peroxynitrite. Biochemistry 35, $7855-7861$.

Marsden, C.D. (1983) Neuromelanin and Parkinson's disease. J. Neural Transm. (Suppl.) 19, $121-141$.

Murphy, M.P. (1999) Nitric oxide and cell death. Biochim. Biophys. Acta 1411, 401-414.

O’Donnell, V.B., Eiserich, J.P., Chumley, P.H., Jablonsky, M.J., Krishna, N.R., Kirk, M., Barnes, S., Darley-Usmar, V.M. \& Freeman, B.A. (1999a) Nitration of unsaturated fatty acids by nitric oxide-derived reactive nitrogen species peroxynitrite, nitrous acid, nitrogen dioxide, and nitronium ion. Chem. Res. Toxicol. 12, 83-92.

O’Donnell, V.B., Eiserich, J.P., Bloodsworth, A., Chumley, P.H., Kirk, M., Barnes, S., Darley-Usmar, V.M. \& Freeman, B.A. (1999b) Nitration of unsaturated fatty acids by nitric oxide-derived reactive species. Methods Enzymol. 301, 454-470.

Odh, G., Carstam, R., Paulson, J., Wittbjer, A., Rosengren, E. \& Rorsman, H. (1994) Neuromelanin of the human substantia nigra: A 
mixed-type melanin. J. Neurochem. 62, 2030-2036.

Okun, M.R. (1997) The role of peroxidase in neuromelanin synthesis: A review. Physiol. Chem. Phys. Med. NMR 29, 15-22.

Patel, R.P., McAndrew, J., Sellak, H., White, R., Jo, H., Freeman, B.A. \& Darley-Usmar, V.M. (1999) Biological aspects of reactive nitrogen species. Biochim. Biophys. Acta 1411, 385-400.

Pfeiffer, S., Schmidt, K. \& Mayer, B. (2000) Dityrosine formation outcompetes tyrosine nitration at low steady-state concentrations of peroxynitrite. Implications for tyrosine modification by nitric oxide/superoxide in vivo. $J$. Biol. Chem. 275, 6346-6352.

Radi, R., Beckman, J.S., Bush, K.M. \& Freeman, A. (1991) Peroxynitrite-induced membrane lipid peroxidation: The cytotoxic potential of superoxide and nitric oxide. Arch. Biochem. Biophys. 288, 481-487.

Radi, R., Denicola, A. \& Freeman, B.A. (1999) Peroxynitrite reactions with carbon dioxide-bicarbonate. Methods Enzymol. 301, 353367.

Richeson, C.E., Mulder, P. Bowry, V.W. \& Ingold, K.U. (1998) The complex chemistry of peroxynitrite decomposition: New insights. $J$. Am. Chem. Soc. 120, 7211-7219.

Rodgers, A.D. \& Curzon, G. (1975) Melanin formation by human brain in vitro. J. Neurochem. 24, 1123-1129.

Rosei, M.A., Blarzino, C., Foppoli, C., Mosca, L. \& Coccia, R. (1994) Lipoxygenase-catalyzed oxidation of catecholamines. Biochem. Biophys. Res. Commun. 200, 344-350.

Różanowska, M., Sarna, T., Land, E.J. \& Truscott, T.G. (1999) Free radical scavenging properties of melanin. Interaction of eu- and pheo-melanin models with reducing and oxidizing radicals. Free Radical Biol. Med. 26, 518-525.

Sarna, T., Pilas, B., Land, E.J. \& Truscott, T.G. (1986) Interaction of radical from water radiolysis with melanin. Biochim. Biophys. Acta 883, 162-167.
Shen, X.-M. \& Dryhurst, G. (1996) Further insights into the influence of L-cysteine on the oxidation chemistry of dopamine: Reaction pathways of potential relevance to Parkinson's disease. Chem. Res. Toxicol. 9, 751-763.

Smith, M.A., Richey-Harris, P.L., Sayre, L.M., Beckman, J.S. \& Perry, G. (1997) Widespread peroxynitrite-mediated damage in Alzheimer's disease. J. Neurosci. 17, 2653-2657.

Stępień, K., Zajdel, A., Wilczok, A., Wilczok, T., Grzelak, A., Mateja, A., Soszyński, M. \& Bartosz, G. (2000) Dopamine-melanin protects against tyrosine nitration, tryptophan oxidation and $\mathrm{Ca}^{2+}$-ATPase inactivation induced by peroxynitrite. Biochim. Biophys. Acta 1523, 189-195.

Stępień, K., Zajdel, A., Świerczek, G., Wilczok, A. \& Wilczok, T. (1998) Reduction of 13-hydroperoxy-9,11-octadecadienoic acid by dopamine-melanin. Biochem. Biophys. Res. Commun. 244, 781-784.

Szabo, C., Zingarelli, B., O'Connor, M. \& Salzaman, A.L. (1996) DNA strand breakage, activation of poly(ADP-ribose) synthetase, and cellular energy depletion are involved in the cytotoxicity in macrophages and smooth muscle cells exposed to peroxynitrite. Proc. Natl. Acad. Sci. U.S.A. 93, 1753-1758.

Tse, D.C.S., McCreery, R.L. \& Adams, R.N. (1976) Potential oxidative pathways of brain catecholamines. J. Med. Chem. 19, 37-40.

Uppu, R.M. \& Pryor, W.A. (1996) Synthesis of peroxynitrite in a two-phase system using isoamyl nitrite and hydrogen peroxide. Anal. Biochem. 236, 242-249.

Uppu, R.M., Squadrito, G.L. \& Pryor, W.A. (1996) Acceleration of peroxynitrite oxidations by carbon dioxide. Arch. Biochem. Biophys. 327, $335-343$.

van der Vliet, A., Eiserich, J.P., O’Neill, C.A., Halliwell, B. \& Cross, C.E. (1995) Tyrosine modification by reactive nitrogen species: A closer look. Arch. Biochem. Biophys. 319, 341-349.

Wilczok, T., Stepien, K., Dzierzega-Lecznar, A., Zajdel, A. \& Wilczok, A. (1999) Model neuromelanins as antioxidative agents during 
lipid peroxidation. Neurotoxicity Res. 1, 141-147.

Yermilov, V., Rubio, J., Becchi, M., Friesen, M.D., Pignatelli, B. \& Ohshima, H. (1995) Formation of 8-nitroguanine by the reaction of guanine with peroxynitrite in vitro. Carcinogenesis $\mathbf{1 6}$, 2045-2050.

Zhang, F. \& Dryhurst, G. (1995) Reactions of cysteine and cysteinyl derivatives with dopa- mine-o-quinone and further insights into the oxidation chemistry of 5-S-cysteinyldopamine: Potential relevance to idiopathic Parkinson's disease. Bioorg. Chem. 23, 193-216.

Zhang, H., Squadrito, G.L. \& Pryor, W.A. (1997) The mechanism of the peroxynitrite-carbon dioxide reaction probed using tyrosinase. Nitric Oxide 1, 301-307. 